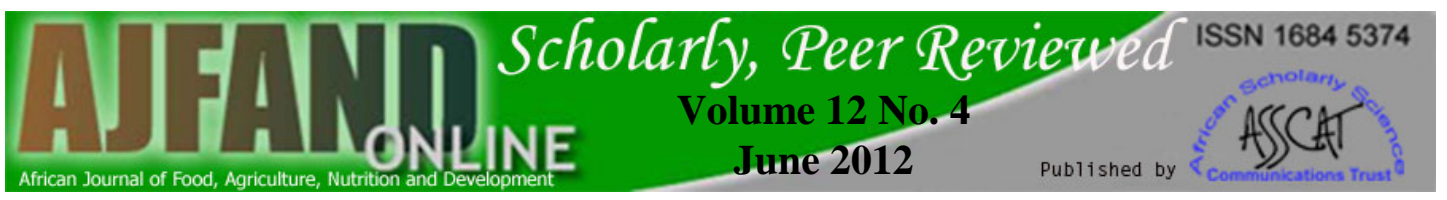

\title{
IMPLEMENTATION OF THE NEW WHO RECOMMENDATIONS ON HIV AND INFANT FEEDING: CHALLENGES AND THE WAY FORWARD
}

\author{
Sagoe-Moses $\mathrm{C}_{1}$, Mwinga K1, Habimana $\mathrm{P}_{1}$, \\ Toure ID 1 and Ketsela $\mathrm{T}_{1}$
}

*Corresponding author email: sagoemosesc@afro.who.int

${ }^{1}$ WHO Regional Office for Africa. 


\section{ABSTRACT}

Breast milk provides all the nutrient needs of the infant especially in the first six months of life and also protects the growing infant from pneumonia, diarrhoea, and malnutrition, which are the major causes of morbidity and mortality in the African Region. However breastfeeding is also known to transmit the Human Immunodeficiency Virus (HIV) from mother to the child. Several guidelines have been developed to guide policy makers, health workers and mothers on the most appropriate methods to feed HIV exposed infants. Previous HIV and infant feeding guidelines emphasized on preventing infants from becoming infected with HIV by counseling HIV-infected mothers to avoid all breastfeeding. Over the period, programme implementers and researchers have reported difficulties in implementing earlier recommendations and guidelines on HIV and infant feeding within health-care systems. New evidence now shows that giving Anti-Retroviral therapy (ARVs) to either the HIV-infected mother or HIV-exposed infant can significantly reduce the risk of transmitting HIV through breastfeeding. Thus, in 2010 World Health Organization (WHO) issued the latest guidelines on HIV and infant feeding entitled Principles and recommendations for infant feeding in the context of HIV and a summary of evidence. The 2010 WHO guidelines have changed the recommendations on how HIV infected mothers should feed their infants, and how health workers should support them. National authorities in each country can decide which infant feeding practice will be primarily promoted and supported by Maternal and Child Health services, i.e. breastfeeding with an antiretroviral intervention to reduce transmission or avoidance of all breastfeeding. Previous guidelines and recommendations on infant feeding in the context of HIV have undergone frequent changes over the past decade. The adaptation and implementation of previous and current guidelines at national level have met challenges. These include lack of consensus among key stakeholders, inadequate funding for the additional cost of providing ARVs to the mother or the child and difficulties in communicating the recommendations in the new guidelines clearly to mothers, health workers and policy makers. To address these challenges a number of proposals have been suggested such as coordinated consensus building process, costing of interventions and a phased implementation approach to ensure successful scale up over time. This paper describes the process of adapting global HIV and infant feeding recommendations and guidelines at national level. It also reviews the challenges encountered in implementation and proposes the way forward in addressing them.

Key words: WHO HIV Infant, Feeding, Recommendations 


\section{INTRODUCTION}

Breast milk is the ideal food for infants. It provides all the nutrients needed by the infant especially in the first six months of life. It also protects the growing infant from pneumonia, diarrhoea, and malnutrition, which are the major causes of morbidity and mortality in the African Region [1,2,3]. However, breastfeeding is also known to transmit Human Immuno-deficiency Virus (HIV) from mother to the child. HIV transmission through breastfeeding could be responsible for over a third of all HIV infections among children if there are no interventions to reduce HIV transmission during pregnancy and delivery, [4.5]. Getting the right balance between the risk of infants being exposed to HIV through breastfeeding and the risk of death from causes other than HIV if infants are not breastfed therefore remains a challenge.

To address this challenge a number of recommendations and guidelines on the most appropriate methods to feed HIV exposed infants have been developed. In the last decade (2000-2010) there has been three such guideline documents produced by WHO on behalf of the UNFPA/UNICEF/WHO/UNAIDS Inter-agency Task Team on Mother-to-child Transmission of HIV. These recommendations and guidelines were issued in 2001, 2006 and 2010. The 2001 guidelines emphasized on preventing infants from becoming infected with HIV by counselling HIV-infected mothers to avoid all breastfeeding. The recommendation stated that "when replacement feeding is Acceptable, Feasible, Affordable, Sustainable, and Safe (AFASS), avoidance of all breastfeeding by HIV-infected mothers is recommended; otherwise, exclusive breastfeeding for the first few months of life is recommended"[6]. Although replacement feeding with infant formula prevents all transmission of HIV through breastfeeding it also increases the risk of death from other causes in many resource poor environments. Programme implementers and researchers reported difficulties in implementing the 2001 and 2006 recommendations and guidelines on HIV and infant feeding within health-care systems. Particularly the lack of clarity on what AFASS meant to the health workers and mothers led to increased mixed feeding of HIV exposed children.

The 2006 revision of the WHO's recommendations and guidelines on infant feeding and HIV was to address some of the problems noted above. It identified exclusive breastfeeding as a safer option than mixed feeding. Exclusive breastfeeding means the infant only receives breast milk without any additional food or drink, not even water) while mixed feeding is defined as the infant receiving breast milk as well as other milks, water or food. Research data on HIV and infant feeding had then become available to back the revision of the 2001 recommendations and guidelines [5,7].

By 2009 there was new evidence to show that giving Anti-retrovirals (ARVs) to either the HIV-infected mother or HIV-exposed infant can significantly reduce the risk of transmitting HIV through breastfeeding [8,9]. Thus the 2010 recommendations were developed through the WHO guideline development process which took consideration of the available evidence, including Grading of Recommendations Assessment, Development and Evaluation (GRADE) methodology, systematic reviews, riskbenefit analysis, the potential impact of the recommendations on human rights issues,

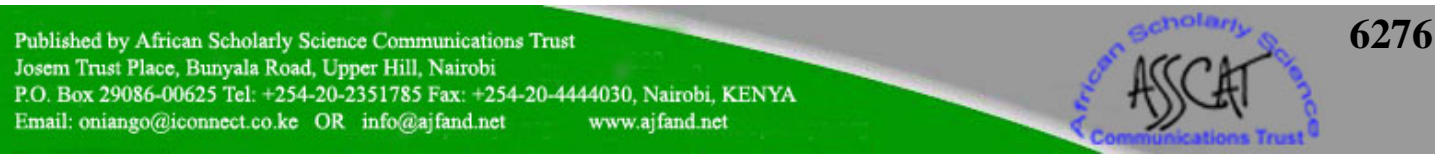


and costs. These findings and other programmatic experiences have informed the current 2010 revised recommendations and guidelines. Principally, it has changed how HIV infected mothers should feed their infants, and how health workers should support them [11].

In 2010 WHO issued the latest guidelines on HIV and infant feeding entitled Principles and recommendations for infant feeding in the context of HIV and a summary of evidence. These guidelines state that national health authorities should promote a single infant feeding practice as the standard of care. While information about other practices should be made available to mothers, health services would mainly support one approach. This is a major difference from the 2006 WHO recommendations on HIV and Infant feeding which suggested that health workers in clinics should individually counsel all mothers known to be HIV-infected, who would then each determine the most appropriate infant feeding strategy for their circumstances $[10,11]$.

This paper describes the process of adapting the 2010 global HIV and infant feeding recommendations and guidelines at national level. It also reviews the challenges encountered in implementing previous and current guidelines and proposes the way forward in addressing these challenges.

\section{Adaptation process for the WHO $2010 \mathrm{HIV}$ and infant feeding guidelines}

The WHO Guideline Development Group met to review and update the 2010 recommendations and guidelines on infant feeding in the context of HIV. The meeting was coordinated with similar but separate meetings to update the guidelines for the use of ARV interventions to prevent mother to child transmission of HIV and guidelines on Anti-retroviral Therapy for HIV infected adults and children. A number of participants took part in all the three meetings. This process was significant as it demonstrated good coordination and collaboration between various stakeholders and ensured coherence among all the four HIV related guidelines.

Following this, the WHO Regional Office for Africa conducted orientation workshops on all the revised guidelines for countries in the three sub-regions (East and Southern Africa, West Africa and Central Africa). The orientation workshops were conducted in collaboration with partners, including: UNICEF, Clinton Foundation, President's Emergency Plan For AIDS Relief (PEPFAR), International Baby Food Action Network (IBFAN) and United States Agency for International Development (USAID).

In East and Southern Africa, more than 150 participants attended the orientation workshop from 15 countries. The West African sub-regional workshop brought together 27 participants from 6 countries ${ }^{\mathrm{ii}}$ and another 47 participants from 6

\footnotetext{
${ }^{\text {i } B o t s w a n a, ~ E r i t r e a, ~ E t h i o p i a, ~ K e n y a, ~ L e s o t h o, ~ M a l a w i, ~ M o z a m b i q u e, ~ N a m i b i a, ~ N i g e r i a, ~ R w a n d a, ~}$ Swaziland, Tanzania, Uganda, Zambia and Zimbabwe

${ }^{\text {ii }}$ Burkina, Cote d'Ivoire, Ghana, Mali, Nigeria and Togo
} 
countries $^{\mathrm{iii}}$ attended the meeting in Central Africa. In addition to disseminating the revised guidelines, the meetings provided technical guidance for country adaptation of the guidelines. The potential impact of the new guidelines on national programs, particularly implications for the existing health systems was discussed and solutions to overcome potential challenges duly considered. From the workshop, countries developed draft action plans on how to implement the guidelines.

Eight countries ${ }^{\text {iv }}$ have since conducted national adaptations on all the four guidelines in a coordinated manner with support from WHO and other partners. In Nigeria a national consultation was held for nutritionists, dietitians, obstetricians and paediatricians who were members of the national Prevention of Mother To Child Transmission PMTCT technical task team, members of the Federal Ministry of Health's divisions of nutrition, child health and HIV/AIDS as well as implementing partners and UN agencies. The meeting concluded by issuing a consensus statement on infant feeding in the context of HIV in Nigeria which called for the development of an implementation framework to support the scaling up of the recommendations and a comprehensive communication strategy to explain the recommendations to all relevant stakeholders.

The adaptation meeting in Botswana was attended by representatives from several departments of the Ministry of Health $(\mathrm{MOH})$, University of Botswana and private paediatricians The meeting agreed that programmatic experience and data should be collected through a planned five-district pilot study and impact study to inform the most effective way to implement and support the new recommendations at scale. However the critical issues raised were the additional cost of revising ART eligibility criteria for pregnant HIV-infected women to CD4<350; providing triple ARV prophylaxis as interventions to prevent postnatal transmission; and promote child survival. In Botswana adopting the WHO recommendations would result in an additional 16\% pregnant HIV-infected women becoming eligible for ART [3].

South Africa has already revised their PMTCT guidelines and made changes to the infant feeding sections. The new guidelines recommend the continued provision of free formula milk through public health facilities for women opting not to breastfeed. Doherty et al argue that the new guidelines did not determine which feeding practice will maximize HIV-free survival nationally [12]. A choice between two feeding options (exclusive breastfeeding or exclusive feeding with free formula milk) is still recommended. This implies that the Government's continuous provision of free commercial infant formula could be an incentive that may lead to confusion in infant feeding decisions of some mothers.

\section{What is new about the WHO 2010 Revised Guidelines?}

The WHO 2010 guidelines include nine guiding principles and seven revised recommendations. The guiding principles define the values and context within which

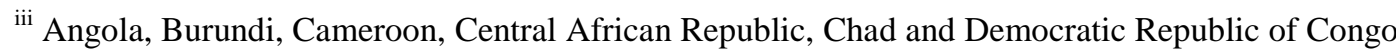

${ }^{\text {iv }}$ Botswana, Cameroon, Ethiopia, Kenya, Namibia, Nigeria, Tanzania and Zimbabwe
} 
recommendations are implemented. They take into considerations relevant programmatic experiences, while the recommendations are based on the best available evidence.

Though the 2010 guidelines build on previous guidelines clarifying some concepts such as AFASS, it also introduces new concepts including the following:

The provision of antiretroviral (ARV) interventions to either the HIV-infected mother or HIV-exposed infant can significantly reduce the risk of postnatal transmission of HIV through breastfeeding [11]. Therefore mothers known to be HIV-infected should now be provided with lifelong antiretroviral therapy or antiretroviral prophylaxis interventions $[13,14]$. National authorities in each country can decide which infant feeding practice, i.e. breastfeeding with an antiretroviral intervention to reduce transmission or avoidance of all breastfeeding, will be primarily promoted and supported by Maternal and Child Health services. This differs from the previous recommendations in which health workers were expected to individually counsel all HIV-infected mothers about the various infant feeding options, and then mothers had to decide which to adopt. [11].

Where ARVs are available, mothers known to be HIV-infected are now recommended to exclusively breastfeed their infants for the first six months of life, introducing appropriate complementary foods thereafter, and continue breastfeeding for the first 12 months of life. Breastfeeding should then only stop once a nutritionally adequate and safe diet without breast milk can be provided [15].

Mothers who decide to stop breastfeeding should stop gradually within one month; stopping breastfeeding abruptly is not advisable [16,17].

\section{What is the added value of the new guidelines?}

Breastfeeding is the predominant mode of feeding infants in most resource poor countries especially in the African Region. The fact that ARV intervention can make breastfeeding safer and reduce the risk of HIV transmission is of significant importance in environments where (AFASS) conditions for safe replacement feeding are difficult to achieve. Breastfeeding of HIV exposed infant improves their HIV-Free survival chances and an important contribution towards child survival. The new guidelines give national authorities adequate basis to decide on the predominant infant feeding practice that would be supported and promoted. When such decision is taken centrally it gives both health workers and mother a certain degree of relief from the stress of making the decisions themselves and removes the uncertainty of how and who will provide the needed support for the implementation of the decision. Mothers will be particularly spared the burden of responsibility associated with making their infant feeding choice when they were not assured of the resources and support to implement it [20].

HIV exposed infants who breastfeed beyond 6 months have a better chance to survival than those who don't [15]. Continuing breastfeeding to 12 means that abrupt cessation of breastfeeding at 6 months with all the challenges for both mother and 
baby is no longer necessary as was the recommendation in 2006. This ensures that the mother - baby pair can gradually stop breastfeeding within a period of one month.

\section{Experience and challenges of implementing HIV and infant feeding guidelines}

Evidence-based knowledge and programmatic experience on infant feeding in the context of HIV are rapidly evolving so it is not surprising that since it became known that the HIV virus could be transmitted through breastfeeding, several guidelines and updates have been developed to guide policy makers, health workers and mothers on the most appropriate methods to feed HIV exposed infants $[18,19,20]$. Sometimes before a global guideline is adapted and fully implemented in the country, a new version is already available.

Disagreement among various national stakeholders has led to the absence of national consensus on global guidelines. This has resulted in mix messages, confusion, and poor counseling of mother. The fear and confusion the HIV infected mother faces in tackling her own HIV status and the possibility of infecting her baby has driven some mothers to choose replacement feeding even when it was obvious that they could not meet the AFASS condition. These mothers eventually resort to mixed feeding with replacement feeding and breastfeeding. The difficulties in accepting the concept of exclusive breastfeeding or exclusive formula feeding for the HIV exposed infant in the first six months of life has led to un-compliance with national guidelines. The involvement of male partners in infant feeding decision making is critical in most African countries. However, counseling and messages on feeding of HIV exposed children exclude men. The HIV infected mother needs all available support to take care of herself and her baby and a male partner who fully understands her infant feeding choice is a great help. When making infant feeding decision, some mothers go through psycho-social distress due to the heavy burden of responsibility of achieving recommended infant feeding advice to avoid HIV transmission that is felt to be downloaded on mothers with the least capacity to implement them $[21,22,23]$. The above are some of the reasons that have led to differences between infant feeding practices and the previous WHO guidelines on HIV and infant feeding [24].

One of the difficulties of implementing global guidelines at national (MOH) level in the past has been how local adaptation was done. The adaptation process of the HIV and infant feeding guidelines was spearheaded mainly by the Nutrition Division with little involvement of the HIV Division. Thus the concerns of HIV Division were not adequately addressed in the adapted materials. Similarly national adaptation of guidelines for anti retroviral therapy and prophylaxis for both children and adults was done by the HIV Division with minimum participation of Nutrition Division. This vertical adaptation process of national guidelines led to lack of awareness and the beginning of mixed and confused messages by health workers to mothers and the general public.

The current training of health care workers providing PMTCT services does not have enough sessions on infant feeding counselling. The trainings curricula have a few hours to a maximum of one day on infant feeding counselling. Often the sessions on infant feeding are reserved for the last day and mostly rushed through. As a result

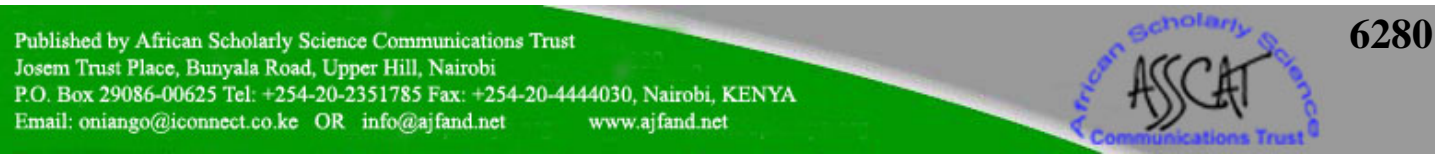


most PMTCT providers were not comfortable counselling mothers on infant feeding. It was not surprising that most of them actively promoted infant formula.

Training in PMTCT has gone faster than infant feeding training. The integrated infant and young child feeding counselling course is the comprehensive training package that provides the necessary knowledge and tools for health workers. Scaling up of this training has been rather slow in most countries with high HIV prevalence. While in these same countries PMTCT training may be scaling up because of the availability of funds from donors such as the Global Fund for AIDS, TB and Malaria and PEPFAR. This imbalance in the number of trained health workers in PMTCT and infant feeding has resulted in fewer experts to support the PMTCT programmes on infant feeding issues.

Networking among PMTCT providers and trained infant feeding counsellors even in the same health facility is poor. Referrals between these two cadres are not well established, mothers who need more detailed infant feeding counselling may not be referred for appropriate counselling.

Updating current PMTCT protocols with the 2010 WHO guidelines will have budget implications. The provision of ARVs to mothers during the breastfeeding period would incur additional start-up costs and thus higher drug costs for the programme, however, the subsequent operational costs to support breastfeeding and ARVS would be significantly less than providing formula milk. There is additional cost of revising ART eligibility criteria for pregnant HIV-infected women to CD4<350 and to provide triple ARV prophylaxis to prevent postnatal transmission and promote child survival. In Botswana for example, adopting the WHO recommendations would result in an additional $16 \%$ pregnant HIV-infected women becoming eligible for ART. Presently, about 31\% HIV-infected pregnant women are thought to have CD4<250 and eligible for ART; this would increase to about $47 \%$ if eligibility criteria moved to CD4<350 [25].

The knowledge and attitudes of health workers, public health messaging and community perceptions significantly influence the infant feeding practices of all mothers (HIV-infected and uninfected). Regardless of the feeding practice recommended for HIV-exposed infants by health authorities, if women are to exercise choice in how they feed their infant, then there should be accurate information on the following: i) the transmission risks associated with breastfeeding if women are receiving effective ARV prophylaxis, ii) the risks of serious morbidity and mortality associated with not breastfeeding, iii) the support available from health services in assisting mothers in their feeding practice and also the interventions needed and available if infants become ill, and, iv) the autonomy within their community and household to implement their decision.

In the past communicating messages on infant feeding in the context of HIV was bedevilled with inaccurate information. Health workers were found to significantly over-estimate the risk of HIV transmission through breastfeeding while the risks of non-breastfeeding were rarely communicated to mothers even though reports of high

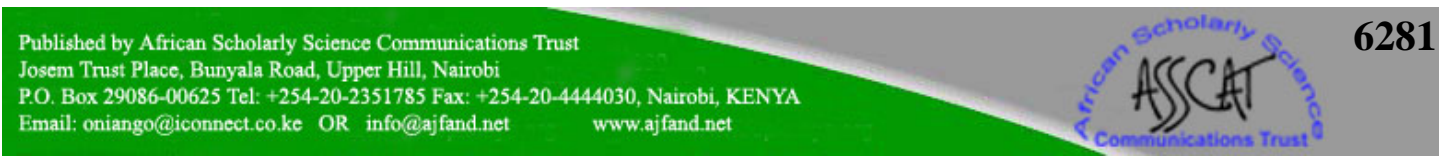


mortality have been reported among infants who were formula fed [26]. All countries need comprehensive communications strategy to inform health workers and communities of the basis for change and to ensure that accurate information including the importance of food hygiene is given to mothers.

\section{WAY FORWARD}

\section{Financial implications of revising current PMTCT protocol}

To address the concerns about additional cost of providing ARV to prevention transmission an estimate of the cost of commodities over the short-term, medium-term and long term should be done. For countries that provide free formula but want to introduce breastfeeding with ARV intervention, a phased approach by gradual withdrawal of formula is advised. Additional costs related to initial training/support and for communication strategies should also be estimated.

In figure 1 data from the PMTCT programme of one country (which currently provides formula milk to all HIV infected mothers) in the African Region was used to prepare a potential budget forecast (commodity cost only) of possible short term, medium term and long term periods. The forecast examined provides Combivir and NVP as the ARV prophylaxis. The following assumptions were made:

Short-term: Year 1: Women in need of lifelong ART $(\mathrm{CD} 4<350)$ receive full ART package. Other women receive triple ARVs through pregnancy starting from 14 weeks. Infants receive 6 wks AZT. 90\% mothers give their infants formula milk and $10 \%$ breastfeed. Women who are not eligible for ART and breastfeeding receive triple ARV prophylaxis for $12 \mathrm{~m}$.

Medium term: Years 2-3: The same as above but 50\% mothers breastfeed and $50 \%$ give formula milk.

Long- term: Years 4-5: The same as above but 100\% mothers breastfeed and no formula milk. 

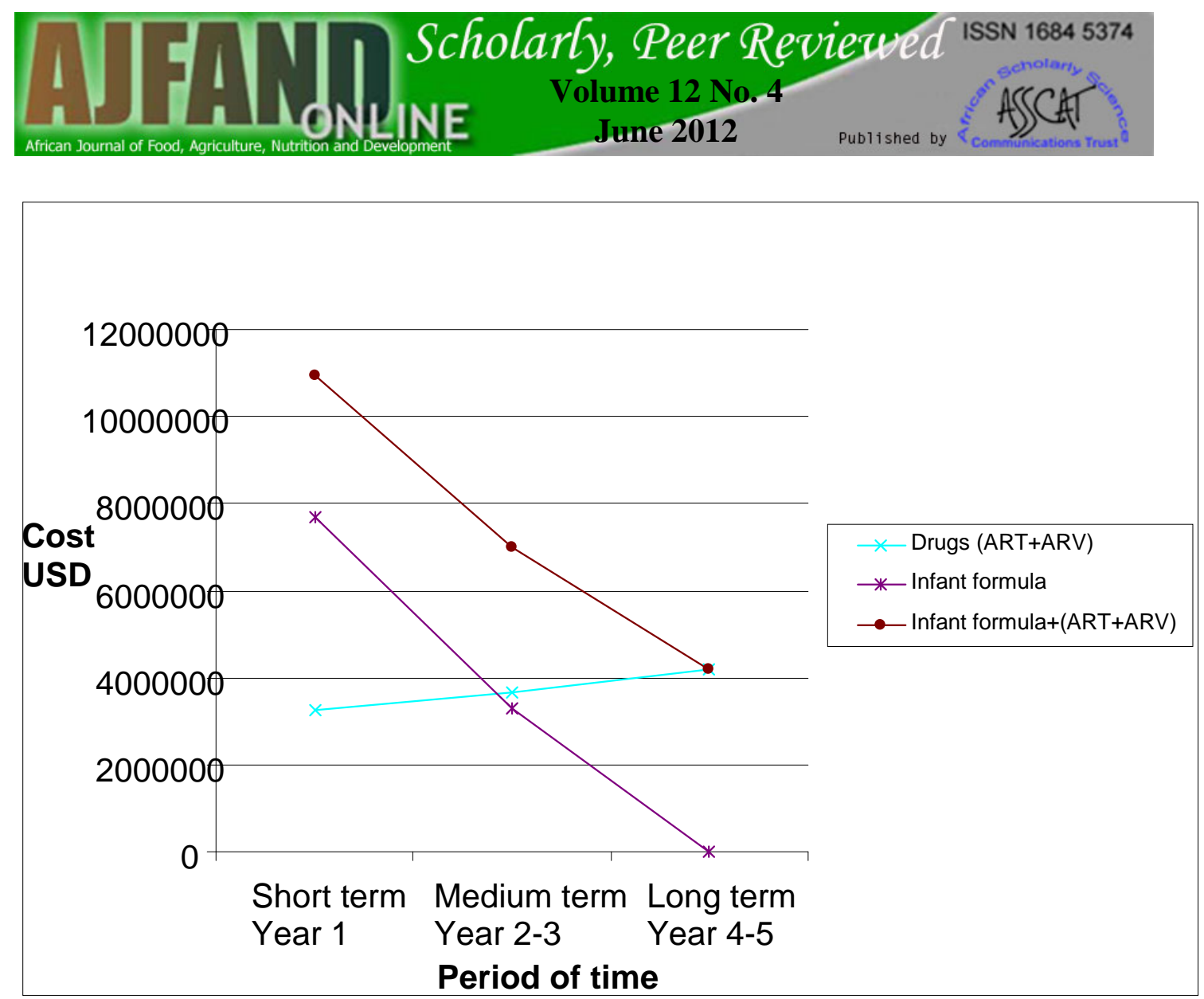

Source: Data from PMTCT Programme of one country providing free formula to HIV exposed infants.

Figure 1: Graph comparing the cost (over a period of time) of providing infant formula with breastfeeding and ARV (Combivir + NVP)

Figure 1 shows that short term costs are more than the long term. Over time, providing ARVs to all breastfeeding mothers costs less than half of providing formula milk to "all” (where "all” mean the short term, with 90\% mothers giving their infants formula milk). The major cost driver in the overall cost is the formula milk.

It is also important to note that this budget forecast is for only commodity cost. Future estimates of cost-effectiveness of investments made in PMTCT should consider other cost such as initial training for health workers and for communications strategies. The estimates should also reflect lifetime gains due to HIV free survival DisabilityAdjusted Life Years (DALYs) rather than just cost per infection averted.

\section{Develop and implement a phased implementation approach.}

There is strong evidence that breastfeeding and ARVs can improve HIV free survival of HIV-exposed infants; however, experience of how to scale-up this approach is minimal. The introduction of major changes in infant feeding recommendations for HIV-infected women and mothers will require a well thought out implementation plan with in-built monitoring and supervision components. This approach should be able to incorporate learning from initial introduction to inform subsequent implementation and scale-up. 
The following are proposed key steps for the phased implementation approach [25]:

A. Develop and implement a phased strategy to introduce breastfeeding with ARV prophylaxis for HIV-infected mothers with short-term (6-12 months), mid-term (12-24 months) and long-term (24-48 months) coverage targets. The approach should devise district level operational plans that incorporate scheduled objective assessments and data feedback to identify solutions to implementation challenges and to optimize maternal and child health outcomes.

B. Planning and implementation of the above strategy should be undertaken jointly by the HIV/PMTCT team together with the nutrition and MCH teams in the $\mathrm{MOH}$.

C. Introduction of Breastfeeding and ARVs for HIV-infected mothers should capitalize on, and be informed by quality improvement approaches that i) use early learning platforms in the short-term to, ii) guide expansion to additional sites in the mid-term, and iii) lead to scale-up and consolidation in all sites in the longer term.

D. Link up interventions directed at HIV-infected women and mothers to other related interventions to improve infant feeding practices in the general population with the aim of reducing infant under-nutrition and reducing infant and child mortality rates nationally.

\section{Develop a comprehensive national communications strategy}

A comprehensive communication strategy is needed for advocacy and to inform key opinion leaders, health workers, communities (pregnant women/mothers) about optimal infant feeding practices and ARV interventions available through health facilities to reduce HIV transmission through breastfeeding. The major recommendations include:

A. Design and implement an effective communication strategy to correct the knowledge of health workers and inform about opportunity to improve HIV free survival of infants through breastfeeding and ARVs;

B. Position HIV-free survival of infants and improved health and survival of mothers as the primary goal of integrated HIV care and treatment interventions;

C. Link with communications to support improving infant feeding in the general population including active awareness creation campaigns to inform mothers about the changes in infant feeding practices and explain the child survival benefits of the changes;

D. Develop parallel communication strategies for policy makers including opinion leaders in medical/nursing professions; implementers such as health workers; and the communities including mothers and the general population, see Table 1. 


\section{Capacity building of health workers}

The competences of health workers need to be aligned with the new guidelines. Training a critical mass of health workers to ensure that correct and accurate information is provided to mothers is very important. Trained health workers will need to be followed up and supported at their place of work to effectively implement their knowledge and skills. The content of training materials needs urgent revision and the curricula of training institutions should be reviewed to take account of the changes.

\section{Improving the links between the community and the health facility}

It has long been recognized that community support for infant feeding practices need strengthening, however, the links between the community and the health facility equally require attention. This is especially so now because supporting breastfeeding and ARV prophylaxis is critical. Mothers and their babies will need regular follow up and support to ensure compliance with ARVs and report side effects and complications of the medicines. The capacity of peer counsellors, mother support groups and community health workers need to be strengthened to support mothers in the community and be a potential bridge for the mothers to quickly access services at the health facilities.

\section{Documentation of best practices}

Programmatic experience of the adaptation and implementation of the 2010 guidelines need to be documented for future planning and programme improvement. Lessons learned at country level should be used to inform the scaling up plans.

\section{CONCLUSION}

The 2010 WHO guidelines on HIV and infant feeding highlight the importance of going beyond preventing mother to child transmission of HIV virus to HIV free survival of the child. By providing ARVs to either the mother or the child, breastfeeding is made safer because the transmission rate is greatly reduced while the child benefits from optimal nutrition and is protected from infections. The adaptation and implementation of guidelines at national level have met challenges including funding the additional cost of ARVs and communicating the recommendations in the new guidelines clearly to mothers, health workers and policy makers. To address these challenges a phased implementation approach has been proposed to ensure successful scaling up over time. Providing ARVs and supporting breastfeeding will ensure HIV free survival of HIV exposed children in the Region and thus contribution towards the achievement of MDG 4. 


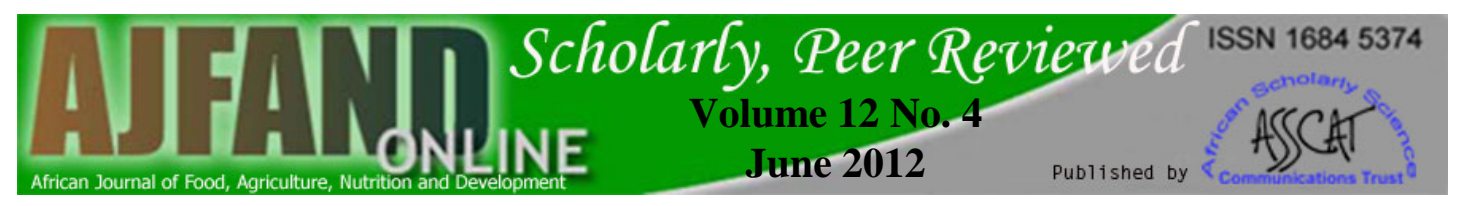

\section{Table 1. Proposed Messages from the Revised WHO guidelines/ recommendations on Infant Feeding and HIV 2010**}

\begin{tabular}{|c|c|c|c|}
\hline Recommendations & Community & Implementers & Policymakers \\
\hline $\begin{array}{l}\text { 1. Ensuring mothers receive the care they } \\
\text { need } \\
\text { Mothers known to be HIV-infected should } \\
\text { be provided with lifelong ART or ARV } \\
\text { prophylaxis interventions to reduce HIV } \\
\text { transmission through breastfeeding } \\
\text { according to WHO recommendations. }\end{array}$ & $\begin{array}{l}\text { All pregnant women should seek } \\
\text { antenatal care early (within the first } \\
3 \text { months) to know their HIV status } \\
\text { and if positive get treatment from } 14 \\
\text { weeks to help prevent transmission } \\
\text { to their babies. Pregnant women } \\
\text { already on AIDS treatment should } \\
\text { continue to seek care to protect their } \\
\text { babies. }\end{array}$ & $\begin{array}{l}\text { All pregnant women should seek } \\
\text { Antenatal care early in the } 1^{\text {st }} \\
\text { trimester to know their HIV status. } \\
\text { HIV positive pregnant women } \\
\text { should start ARV prophylaxis } \\
\text { from } 14 \text { weeks to prevent MTCT. } \\
\text { If a pregnant woman is already } \\
\text { on antiretroviral treatment, she } \\
\text { should get continued care to } \\
\text { ensure optimal treatment to } \\
\text { protect her baby }\end{array}$ & $\begin{array}{l}\text { Virtual elimination of MTCT can be } \\
\text { achieved through the early use of } \\
\text { more effective drugs. } \\
\text { More HIV positive pregnant } \\
\text { women will now be eligible for } \\
\text { earlier treatment. HIV positive } \\
\text { pregnant women not yet on } \\
\text { treatment will receive ARV } \\
\text { prophylaxis to prevent MTCT }\end{array}$ \\
\hline $\begin{array}{l}\text { 2. Which breastfeeding practices and for } \\
\text { how long } \\
\text { In settings where national or sub-national } \\
\text { authorities have decided that maternal, } \\
\text { newborn and child health services will } \\
\text { principally promote and support } \\
\text { breastfeeding and ARV interventions } \\
\text { Mothers known to be HIV-infected (and } \\
\text { whose infants are HIV uninfected or of } \\
\text { unknown HIV status) should exclusively } \\
\text { breastfeed their infants for the first } 6 \\
\text { months of life, introducing appropriate } \\
\text { complementary foods thereafter, and } \\
\text { continue breastfeeding for the first } 12 \\
\text { months of life. Breastfeeding should then } \\
\text { only stop once a nutritionally adequate } \\
\text { and safe diet without breast milk can be } \\
\text { provided. }\end{array}$ & $\begin{array}{l}\text { HIV positive mothers should [now] } \\
\text { breastfeed exclusively (give } \\
\text { breastmilk only) for the first } 6 \\
\text { months. After } 6 \text { months introduce } \\
\text { other foods (complementary foods) } \\
\text { and continue to breastfeed up to } 12 \\
\text { months while receiving HIV drugs } \\
\text { (ARV) to improve the baby's } \\
\text { chances of survival and reduce the } \\
\text { risk of HIV transmission to her baby. } \\
\text { After } 12 \text { months nutritionally } \\
\text { adequate and safe diet without } \\
\text { breast milk should be provided. }\end{array}$ & $\begin{array}{l}\text { HIV positive mothers should } \\
\text { [now] breastfeed exclusively for } \\
\text { the first } 6 \text { months. After } 6 \text { months } \\
\text { introduce complementary foods } \\
\text { and continue to breastfeed up to } \\
12 \text { months while the baby or the } \\
\text { mother is on ARVs to improve } \\
\text { the baby's chance of survival and } \\
\text { reduce the risk of HIV } \\
\text { transmission. After } 12 \text { months } \\
\text { nutritionally adequate and safe } \\
\text { diet without breast milk should be } \\
\text { provided. }\end{array}$ & $\begin{array}{l}\text { Child survival can be improved } \\
\text { while achieving virtual elimination } \\
\text { of MTCT. HIV positive mothers } \\
\text { should [now] breastfeed } \\
\text { exclusively for the first } 6 \text { months, } \\
\text { and continue to breastfeed with } \\
\text { (complementary foods) to } 12 \\
\text { months while the baby or the } \\
\text { mother is on ARV to improve the } \\
\text { babies chance of survival while } \\
\text { reducing the risk of HIV } \\
\text { transmission. After } 12 \text { months } \\
\text { nutritionally adequate and safe diet } \\
\text { without breast milk should be } \\
\text { provided. }\end{array}$ \\
\hline $\begin{array}{l}\text { 3. When mothers decide to stop } \\
\text { breastfeeding } \\
\text { In settings where national or sub-national } \\
\text { authorities have decided that maternal, } \\
\text { newborn and child health services will } \\
\text { principally promote and support } \\
\text { breastfeeding and ARV interventions } \\
\text { Mothers known to be HIV-infected who } \\
\text { decide to stop breastfeeding at any time } \\
\text { should stop gradually within one month. } \\
\text { Mothers or infants who have been } \\
\text { receiving ARV prophylaxis should } \\
\text { continue prophylaxis for one week after } \\
\text { breastfeeding is fully stopped. Stopping } \\
\text { breastfeeding abruptly is not advisable. }\end{array}$ & $\begin{array}{l}\text { HIV positive mothers who decide to } \\
\text { stop breastfeeding at any time } \\
\text { should do so gradually [within] over } \\
\text { one month. Mothers or infants who } \\
\text { have been receiving HIV drugs } \\
\text { (ARV prophylaxis) should continue } \\
\text { on these for one week after } \\
\text { breastfeeding is fully stopped. } \\
\text { Stopping breastfeeding suddenly is } \\
\text { not recommended. }\end{array}$ & $\begin{array}{l}\text { HIV positive mothers who decide } \\
\text { to stop breastfeeding at any time } \\
\text { should stop gradually [within] } \\
\text { over one month. } \\
\text { Mothers or infants who have } \\
\text { been receiving ARV prophylaxis } \\
\text { should continue prophylaxis for } \\
\text { one week after breastfeeding is } \\
\text { fully stopped. Stopping } \\
\text { breastfeeding abruptly is not } \\
\text { advisable. }\end{array}$ & $\begin{array}{l}\text { Prior guidance for abrupt } \\
\text { caessation of breastfeeding for } \\
\text { HIV positive mothers has been } \\
\text { replaced with recommendation for } \\
\text { gradual stopping of breastfeeding } \\
\text { over one month period to ensure } \\
\text { optimal nutrition and improved } \\
\text { child survival. ARVs should } \\
\text { continue for one after } \\
\text { breastfeeding has fully stopped }\end{array}$ \\
\hline $\begin{array}{l}\text { 4. What to feed infants when mothers stop } \\
\text { breastfeeding } \\
\text { In settings where national or sub-national } \\
\text { authorities have decided that maternal, } \\
\text { newborn and child health services will } \\
\text { principally promote and support } \\
\text { breastfeeding and ARV interventions } \\
\text { When mothers known to be HIV-infected } \\
\text { decide to stop breastfeeding at any time, } \\
\text { infants should be provided with safe and } \\
\text { adequate replacement feeds to enable } \\
\text { normal growth and development. } \\
\text { Alternatives to breastfeeding include: }\end{array}$ & $\begin{array}{l}\text { When an HIV positive mother } \\
\text { decides to stop breastfeeding at any } \\
\text { time, the baby should be provided } \\
\text { with safe and adequate replacement } \\
\text { feeds to enable normal growth and } \\
\text { development. For babies below } 6 \\
\text { months the options include } \\
\text { commercial infant formula or the use } \\
\text { of expressed breast milk that is heat } \\
\text { treated. Animal milk is not } \\
\text { recommended for feeding babies } \\
\text { younger than six months. } \\
\text { For children over six months }\end{array}$ & $\begin{array}{l}\text { When an HIV positive mother } \\
\text { decides to stop breastfeeding at } \\
\text { any time, infants should be } \\
\text { provided with safe and adequate } \\
\text { replacement feeds to enable } \\
\text { normal growth and development. } \\
\text { For babies below } 6 \text { months the } \\
\text { options include commercial infant } \\
\text { formula or the use of expressed } \\
\text { breastmilk that is heat treated. } \\
\text { Animal milk is not recommended } \\
\text { for feeding babies younger than } \\
\text { six months. }\end{array}$ & $\begin{array}{l}\text { Animal milk is no longer } \\
\text { recommended as a suitable } \\
\text { alternative for children under } 6 \\
\text { months of age. HIV positive } \\
\text { mothers who decide to stop breast } \\
\text { feed can have the following } \\
\text { alternatives: For infants less than } \\
\text { six months of age: Commercial } \\
\text { infant Formula or EHT-Breast milk } \\
\text { For children over six months of } \\
\text { age: Commercial Formula or } \\
\text { Animal milk }\end{array}$ \\
\hline
\end{tabular}

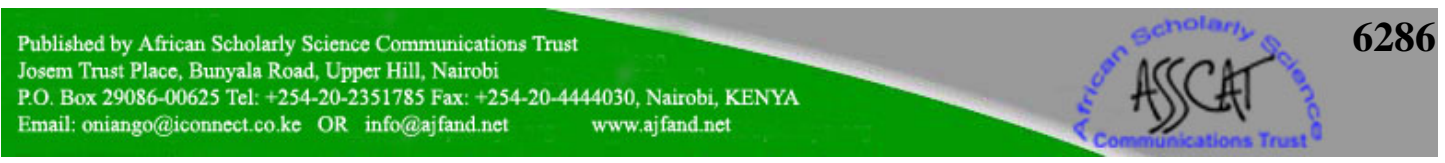




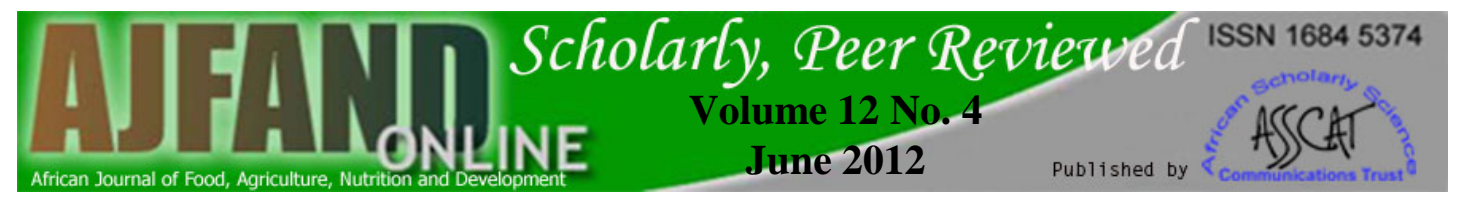

\begin{abstract}
For infants less than six months of age:
Commercial Formula or EHT-Breast milk

For children over six months of age:

Commercial Formula or Animal milk

5. Conditions needed to safely formula

feed
\end{abstract}

Mothers known to be HIV-infected should only give commercial infant formula milk as a replacement feed to their HIVuninfected infants or infants who are of unknown HIV status, when specific conditions are met:

a. safe water and sanitation are assured at the household level and in the community; and

b. the mother, or other caregiver can reliably provide sufficient infant formula milk to support normal growth and development of the infant; and c. the mother or caregiver can prepare it cleanly and frequently enough so that it is safe and carries a low risk of diarrhoea and malnutrition; and

$d$. the mother or caregiver can, in the first six months, exclusively give infant formula milk; and

e. the family is supportive of this practice; and

$\mathrm{f}$. the mother or caregiver can access health care that offers comprehensive child health services.

6. Heat-treated, expressed breast milk Mothers known to be HIV-infected may consider expressing and heat-treating breast milk as an interim feeding strategy: - in special circumstances such as when the infant is born with low birth weight or is otherwise ill in the neonatal period and unable to breastfeed; or

-when the mother is unwell and

temporarily unable to breastfeed or has a temporary breast health problem such as mastitis; or

-to assist mothers to stop breastfeeding; or

- if antiretroviral drugs are temporarily not available.

7. When the infant is HIV-infected If infants and young children are known to be HIV-infected, mothers are strongly encouraged to exclusively breastfeed for the first six months of life and continue breastfeeding as per the recommendations for the general population, that is, up to two years or beyond. commercial infant formula or animal milk can be used.

If HIV positive mothers decide to give commercial infant formula milk as a replacement feed to their babies the following conditions must all be in place:

a. the home and community should have constant supply of safe water and sanitation facilities; and b. mother, or other caregiver should ensure sufficient and continuous supply of commercial infant formula to support normal growth and development of the infant; and c. the mother or caregiver can prepare the milk cleanly and frequently enough to reduce the risk of diarrhoea and malnutrition; and

d. the mother or caregiver can give only infant formula milk, in the first six months; and

e. the family is supportive of this practice; and

f. the mother or caregiver can regularly take the child to health facilities for care.

Heat treating breast milk can be used for a short period of time by HIV positive mother as an infant feeding option: This can be done if a child is unable to suckle, if a mother is unable to breastfeed for short period or if a mother needs to stop AIDS drugs (ARV) for a short time

\section{If infants and young children are} known to be HIV-infected, mothers are strongly encouraged to give breast milk only (exclusive) for the first six months. After 6 month introduce other foods and continue to breastfeed up to 2 years or beyond.

The mother or caregiver can regularly take the child to health facilities for care.

For children over six months commercial infant formula or animal milk can be used.

If HIV positive mothers decide to give commercial infant formula milk as a replacement feed to their babies the following conditions must all be in place: a. the home and community should have constant supply of safe water and sanitation facilities; and

b. mother, or other caregiver should ensure sufficient and continuous supply of commercial infant formula to support normal growth and development of the infant; and

c. the mother or caregiver can prepare the milk cleanly and frequently enough to reduce the risk of diarrhoea and malnutrition and

d. the mother or caregiver can give only infant formula milk, in the first six months; and

e. the family is supportive of this practice; and

$\mathrm{f}$. the mother or caregiver can regularly take the child to health facilities for care.

\section{Heat-treated, expressed breas}

milk is an interim feeding

strategy:

- in special circumstances such as when the infant is born with low birth weight or is otherwise ill in the neonatal period and unable to breastfeed; or

-when the mother is unwell and temporarily unable to breastfeed or has a temporary breast health problem such as mastitis; or -to assist mothers to stop breastfeeding; or

- if antiretroviral drugs are temporarily not available.

If infants and young children are known to be HIV-infected, mothers are strongly encouraged to exclusively breastfeed for the first six months of life. After 6 months introduce complementary foods and continue breastfeeding up to 2 years or beyond. The mother or caregiver can regularly take the child to health facilities for care.
As an alternative to breastfeeding an HIV positive mother can choose replacement feeding. In order to minimize the associated risk of childhood mortality from diarrhoea and respiratory diseases the follow minimum conditions should be met: These include safe water and sanitation; sufficient supply of infant formula milk; hygienic and adequate preparation; ability for exclusive formula feeding for the first 6 months of life; supportive environment; and access to health care services.

HIV positive mothers or infants in special circumstances can be supported to ensure optimal infant feeding. Heat treated express breast milk can used as an interim feeding strategy to reduce HIV transmission and maximize child survival

For HIV positive infants or young children, feeding recommendations remain the same as the general population. Mothers are strongly encouraged to exclusively breastfeed for the first six months of life. After 6 months introduce complementary foods and continue breastfeeding up to 2 years or beyond. The mother or caregiver can regularly take the child to health facilities for care.

**Proposed messages for a comprehensive communication strategy developed by participants at an IBFAN Africa meeting in September 2010 in Mauritius for country specific field testing and adaptation

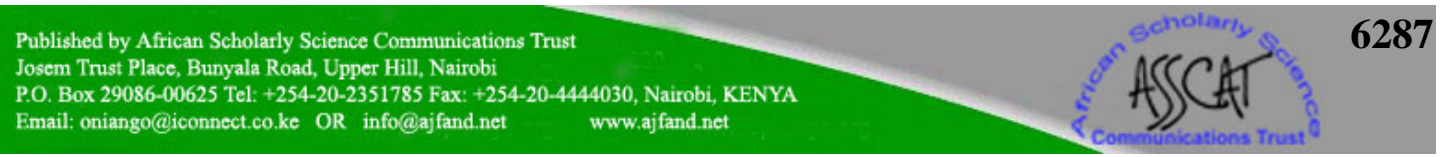




\section{REFERENCES}

1. Duijts L, Jaddoe VW, Hofman A and HA Moll Prolonged and exclusive breastfeeding reduces the risk of infectious diseases in infancy. Pediatrics. 2010; 126(1):e18-25.

2. Mwiru RS, Spiegelman D, Duggan C, Peterson K, Liu E, Msamanga G, Aboud S and WW Fawzi Relationship of exclusive breast-feeding to infections and growth of Tanzanian children born to HIV-infected women. Public Health Nutr. 2011; 16:1-8.

3. Fawzy A, Arpadi S, Kankasa C, Sinkala M, Mwiya M, Thea DM, Aldrovandi GM and L Kuhn Early Weaning Increases Diarrhea Morbidity and Mortality Among Uninfected Children Born to HIV-infected Mothers in Zambia. J Infect Dis. 2011; 203(9):1222-30.

4. Breastfeeding and HIV International Transmission Study Group. Late postnatal transmission of HIV-1 in breast-fed children: an individual patient data meta-analysis. J Infect Dis. 2004;189: 2154-2166.

5. Coovadia HM, Rollins NC, Bland RM, Little K, Bennish ML and ML Newell Mother-to-child transmission of HIV-1 infection during exclusive breastfeeding in the first 6 months of life: an intervention cohort study. Lancet. 2007; 369:1107-1116.

6. World Health Organization. New data on the prevention of mother-to-child transmission of HIV and their policy implications: Conclusions and recommendations. Technical consultation on behalf of the UNFPA/UNICEF/WHO/UNAIDS inter-agency task team on mother-to-child transmission of HIV. WHO, Geneva, 2001.

7. Iliff PJ, Piwoz EG, Tavengwa NV, Zunguza CD, Marinda ET, Nathoo KJ, Moulton LH, Ward BJ, Humphrey JH; ZVITAMBO study group. Early exclusive breastfeeding reduces the risk of postnatal HIV-1 transmission and increases HIV-free survival. AIDS 2005; 19: 699-708.

8. The Kesho Bora Study Group. Triple antiretroviral compared with zidovudine and single-dose nevirapine prophylaxis during pregnancy and breastfeeding for prevention of mother-to-child transmission of HIV-1 (Kesho Bora study): a randomised controlled trial. Lancet Infect Dis. 2011; 11(3):171180.

9. Kesho Bora Study Group. Eighteen-month follow-up of HIV-1-infected mothers and their children enrolled in the Kesho Bora study observational cohorts. Acquir Immune Defic Syndr. 2010;54(5):533-41.

10. WHO, UNAIDS, UNFPA, UNICEF. HIV and Infant Feeding: Update. Based on the Technical Consultation. Technical Consultation held on behalf of the 
Inter-agency Task Team (IATT) on Prevention of HIV Infections in Pregnant Women, Mothers and their Infants, Geneva, Switzerland, 25-27 October 2006. WHO, Geneva, 2007.

11. WHO, UNAIDS, UNFPA, UNICEF. Guidelines on HIV and infant feeding: Principles and recommendations for infant feeding in the context of HIV and a summary of evidence. WHO, Geneva, 2010.

12. Doherty T, Sanders D, Goga A and D Jackson Implications of the new WHO guidelines on HIV and infant feeding for child survival in South Africa. Bulletin of the World Health Organization. 2011;89(1):62-7.

13. Shapiro RL, Hughes MD, Ogwu A, Kitch D, Lockman S, Moffat C, Makhema J, Moyo S, Thior I, McIntosh K, van Widenfelt E, Leidner J, Powis K, Asmelash A, Tumbare E, Zwerski S, Sharma U, Handelsman E, Mburu K, Jayeoba O, Moko E, Souda S, Lubega E, Akhtar M, Wester C, Tuomola R, Snowden W, Martinez-Tristani M, Mazhani L and M Essex Anti-retroviral regimens in pregnancy and breast-feeding in Botswana. $N$ Engl J Med. 2010;362(24):2282-94.

14. Homsy J, Moore D, Barasa A, Were W, Likicho C, Waiswa B, Downing $\mathbf{R}$, Malamba $\mathbf{S}$, Tappero $\mathbf{J}$ and $\mathbf{J}$ Mermin Breastfeeding, mother-to-child HIV transmission, and mortality among infants born to HIV-Infected women on highly active antiretroviral therapy in rural Uganda. $J$ Acquir Immune Defic Syndr. 2010; 53(1):28-35.

15. Kafulafula G, Hoover DR, Taha TE, Thigpen M, Li Q, Fowler MG, Kumwenda NI, Nkanaunena K, Mipando L and LM Mofenson Frequency of gastroenteritis and gastroenteritis-associated mortality with early weaning in HIV-1-uninfected children born to HIV-infected women in Malawi. J Acquir Immune Defic Syndr. 2010; 53(1):6-13.

16. Kuhn L, Aldrovandi GM, Sinkala M, Kankasa C, Semrau K, Kasonde P, Mwiya M, Tsai WYand DM Thea Zambia Exclusive Breastfeeding Study (ZEBS). Differential effects of early weaning for HIV-free survival of children born to HIV-infected mothers by severity of maternal disease. PLoS One. 2009; 26:4(6).

17. Kuhn L, Aldrovandi GM, Sinkala M, Kankasa C, Semrau K, Mwiya M, Kasonde P, Scott N, Vwalika C, Walter J, Bulterys M, Tsai WY and Thea . Zambia Exclusive Breastfeeding Study. Effects of early, abrupt weaning on HIV-free survival of children in Zambia. $N$ Engl J Med. 2008;359(2):130-41.

18. Thiry L, Sprecher-Goldberger $\mathbf{S}$ and $\mathbf{T}$ Jonckheer Isolation of AIDS virus from cell-free breastmilk of three health virus carriers. The Lancet. 1985;ii:891-892. 
19. Ziegler J, Johnson R, Cooper $\mathbf{D}$ and $\mathbf{J}$ Gold. Postnatal transmission of AIDS-associated retrovirus from mother to infant. The Lancet. 1985; 325 (8434):896-898.

20. Moland KM, de Paoli MM, Sellen DW, van Esterik P, Leshabari SC and A Blystad Breastfeeding and HIV: experiences from a decade of prevention of postnatal HIV transmission in sub-Saharan Africa. Int Breastfeed J. 2010 ; 5:10.

21. Levy JM, Webb AL and DW Sellen "On our own, we can't manage": experiences with infant feeding recommendations among Malawian mothers living with HIV. Int Breastfeed J. 2010;5:15.

22. Engebretsen IMS, Moland KM, Nankunda J, Karamagi CA, Tylleskar T and JK Tumwine Gendered perceptions on infant feeding in Eastern Uganda: continued need for exclusive breastfeeding support. Int Breastfeed J. 2010; 5:13.

23. Chinkonde JR, Sundby J, de Paoli M and VC Thorsen The difficulty with responding to policy changes for HIV and infant feeding in Malawi. Int Breastfeed J. 2010; 5:11.

24. Fadnes LT, Engebretsen IM, Wamani H, Wangisi J, Tumwine JK and T Tylleskär Need to optimise infant feeding counselling: a cross-sectional survey among HIV-positive mothers in Eastern Uganda. BMC Pediatr. 2009 ; 9:2

25. World Health Organization. Mission report: Joint WHO/UNICEF consultative meeting on the New WHO recommendation on ART, PMTCT and Infant Feeding in the context of HIV:Gaborone, Botswana. July 2010.

26. Chopra $\mathbf{M}$ and $\mathbf{N}$ Rollins Infant feeding in the time of HIV: rapid assessment of infant feeding policy and programmes in four African countries scaling up prevention of mother to child transmission programmes. Arch Dis Child. 2008; 93:288-291. 